\title{
A theoretical approach to nursing assessment
}

\author{
Janis Campbell MS RN Nurse Consultant, Debra Finch BSN RN Head Nurse, \\ Charlotte Allport BSN RN Staff Nurse, Helen C. Erickson PhD RN Assistant Professor \\ of Nursing and Mary Ann P. Swain PhD Associate Vice President for Academic Affairs and \\ Professor of Nursing, University of Michigan Hospitals, Ann Arbor, Michigan, U.S.A
}

Accepted for publication 12 September 1984

CAMPBELL J., FINCH D., ALLPORT C., ERICKSON H.C. \& SWAIN M.A.P. (1985) Journal of Advanced Nursing 10, 111-115

\section{A theoretical approach to nursing assessment}

Nurses use theory to sharpen their observations and to facilitate their understanding of the human responses to which they direct their interventions. An assessment tool, derived from the nursing theory 'modelling and role-modelling', was developed by nurses at the University of Michigan Hospitals. This tool appears to elicit the data necessary to assess and diagnose the health status of clients. This article describes the assessment tool, why it was developed, the objectives in utilization of the tool and suggestions for implementation.

\section{NURSING}

Nursing is the diagnosis and treatment of human responses to actual or potential health problems. Nurses assess clients to ascertain these human responses, to which they will direct their actions. Theory is utilized to sharpen the nurses' observations and to facilitate their understanding of the human responses (American Nurses' Association 1980). There is a need for instruments based on theory to assist nurses in the identification of human responses. This article describes an assessment tool developed by nurses at the University of Michigan Hospitals. This tool was derived from the nursing theory 'modelling and role modelling' (Erickson et al. 1983).

The method of assessing clients has evolved over the years. One of the most widely accepted methods, the 'functional abilities approach' was pioneered by McCain (1965). More recently, Gordon (1982) proposed the 'functional health patterns' assessment tool. These methods have encouraged nurses to be organized and systematic in their approach. However, these

Correspondence: Janis Campbell, A6037-Box 55, 1405 E. Ann Street, Ann Arbor, Michigan 48109, USA. methods are not based on a nursing theory, which limits their applicability.

For the past 18 months, nurses working on a general surgical unit have utilized the nursing theory 'modelling and role-modelling' in caring for clients. What evolved from their nursing practice was the need for a nursing assessment tool that identified the necessary client responses that enabled the nurse to plan, intervene and achieve desired outcomes. The assessment tool in use at that time was a functional systems approach, which was incompatible with 'modelling and role-modelling'. The information elicited was not useful in planning holistic care and was repetitive of the physician's data. In planning holistic care, the nurse must know how the client perceives his situation, what's important to him, what his expectations are, what his support system is and if these people are available to him, and what the client expects from the nurse. Then the nurse will have the basic data to begin formulating nursing diagnoses and planning purposeful interventions.

The first step in development of this assessment tool was to consider using the format for data collection suggested by 
Erickson et al. (1983). This format is very comprehensive, but needed to be condensed to be useful to the nurses on the unit. As this was done, care was taken to maintain the authors' basic categories and to add only what the nurses decided was necessary for admission to the unit.

Several revisions of the assessment tool have already occurred, and more are expected as the nurses gain experience with utilization of this tool. A study is currently being carried out to test its usefulness in enabling nurses to make nursing diagnoses from the data elicited by the tool. From experiences to date, it appears that this assessment tool merits consideration by members of the nursing profession.

\section{A MODELLING AND ROLE-MODELLING APPROACH}

The goal of nurses in caring for clients is 'to achieve a state of perceived optimum health and contentment' (Erickson et al. 1983). This requires assessing and diagnosing the client's status on several theoretical bases: the degree to which the client's needs are met as defined by Maslow (1970), the resolution of psychosocial developmental tasks as defined by Erikson (1963), the cognitive development, as defined by Piaget (1973), their adaptive potential state, as defined by Erickson and Swain (1982), and resolution of losses as defined by Engel (1964). The nursing assessment needs to provide the nurse with the necessary information to diagnose the client's status in each of these areas. The nurse will then have the data she needs to model the client's world. That is, to interpret the relationships among the diagnoses and to develop a mirror image of the client's situation from his/her perspective. It is then that the nurse can model a healthier world for the patient. She facilitates the client in attaining, maintaining or promoting health through purposeful interventions (Erickson et al. 1983).

Before describing the proposed method of assessment, it seems appropriate to identify certain underlying concepts. The assessment is not an exercise to be completed and placed on the client's chart, never to be referred to again. Rather, it is a tool which can be used to develop or maintain a therapeutic relationship between the nurse and the client. The goals of the assessment are to establish trust in the nurse/ client relationship; intervene by listening, analysing and possibly meeting some immediate needs; and collect information that will be useful in planning nursing interventions. As the client's situation changes, the assessment may need to be repeated in part or whole.

During the assessment, it is important that the client should feel free to elaborate on whatever he sees as a priority at the time. The nurse is intervening as she listens and analyses what the client is saying. The nurse needs to realize the importance of what she is doing, and not feel under pressure to complete all of the assessment at one interview.

The client is the primary and most important source of data and the nurse focuses on his priorities and needs as he identifies them. This does not mean that the nurse ignores the client's safety or physiological needs; but it does mean that the nurse assesses and interviews in those areas that are of concern to the patient. If a patient indicates concern in relation to a particular physiological system, the nurse may determine that she needs to do a physical examination of that system and will indicate this to the client. It is also likely that the client may not express concern in relation to a particular physiological system, and the nurse will not need to do a physical examination.

There are situations in which the nurse collects biophysical data without the client's direction to do so. In acute situations when the client's safety is a priority the nurse would intervene appropriately. In some situations clients are unable to communicate or convey their needs, and the nurse must set priorities based on her knowledge of the client and her expertise.

\section{SUGGESTIONS FOR IMPLEMENTATION}

It is necessary for the client to feel safe, comfortable and assured of his privacy for the interview. The nurse must arrange an appropriate time to assess the client. If her initial data indicates that the client is in pain, is very tired or has other basic needs, it will naturally be her first priority to meet those needs and to complete other aspects of the assessment at a later time.

The nursing assessment is done by the professional nurse. Preferably she will be the 
Category

*Description of the situation

*Expectations

Support resources

Health status

*Strengths

Demographical data
Purpose for data collection

*To develop an overview of the situation from the client's perspective.

To identify the etiological factors involved.

To identify possible therapeutic interventions.

-To develop an understanding of the client's expectations for the present and future.

To determine the current developmental status in order to understand the client's personal model and to utilize maximum communication skills.

*To determine the nature of the external support system.

*To determine the client's perceived health status.

*To determine the client's strengths and virtues.

To determine the client's currently available internal resources.

To collect information necessary for admission to the unit.

*From Modelling and Role-Modelling: A Theory and Paradigm for Nursing (Erickson H., Tomlin E. \& Swain M. A. eds). Reprinted by kind permission of Prentice Hall Inc., New Jersey.

client's primary nurse. Nurses' reports indicate that the relationships they begin to develop with clients from doing the assessment persist throughout the client's hospitalization.

The client's responses are recorded exactly as he conveys them to the nurse, and are recorded in the left column on the assessment form (see Appendix). It is preferable to interview the client without the family present as he may wish to share information that he would not feel comfortable saying in their presence. The family should be interviewed in the client's presence, unless the family or the client request otherwise. This is important in establishing trust with the client. The nurse continually collects verbal and non-verbal data as she assesses the client and the family. These observations and impressions are important and are recorded with the family data in the right column of the assessment form. The nurse analyses the data, identifying the strengths of the client, and formulates nursing diagnoses.

The assessment consists of six major categories: the description of the situation, expectations, support resources, health status, strengths and geographical data. The purposes of data collection in each of these categories are shown in Table 1.
The nurse who is utilizing the assessment needs to feel comfortable with this approach to nursing care. This can best be accomplished when the nurse is knowledgeable about modelling and role-modelling and understands why she is collecting this type of data. The nurses in this study have utilized the theory in caring for many clients during the past year. At client care conferences the nurses discuss the data they've collected, assessing the patient's needs, developmental level, coping state and cognitive level, and often the grieving phenomenon. They have then planned interventions appropriate for the individual client.

In addition to helping the nurses plan for clients, the conferences have stimulated many discussions about what nursing is, nurse-client relationships, nurse-physician relationships, and peer relationships. These conferences have facilitated the nurses in examining their professional values, attitudes and behaviours.

Reactions from clients to the assessment have been positive. Many of the clients have commented to the nurses how much they enjoyed the interview. Several patients have thanked the nurses for helping them when the nurse did nothing further for that client. A few of the clients have had difficulty with the 
terminology of the questions, and the nurses have rephrased some questions to the client's level of understanding.

Reactions from physicians have been positive. They are usually aware that the client has problems that they have neither the time nor the expertise to address.

This tool is being used on all clients admitted to the unit used in this study. Nurses report that this method of assessment meets its intended objectives, as previously defined. They also report that their experiences with 'modelling and role-modelling' and this tool have enhanced their relationships with all clients.

\section{Acknowledgement}

The authors would like to thank the nurses on 7 West ward at the University of Michigan Hospitals and Jenny R. James, Director of Surgical Nursing, who made development of this assessment tool possible by giving so generously of their time and support. The authors would also like to thank Evelyn Tomlin, co-author of Modelling and RoleModelling, $a$ Theory and Paradigm for Nursing, whose ideas and support contributed significantly to the development of this assessment tool.

\section{References}

American Nurses Association (1980) Nursing: A Social Policy Statement. American Nurses Association, Kansas.

Engel G. (1964) Grief and grieving. American Journal of Nursing $65,82-84$.

Erickson H. \& Swain M.A. (1982) A model for assessing potential adaptation to stress. Research in Nursing and Health 5, 93-101.

Erickson H., Tomlin E. \& Swain M.A. (1983) Modelling and RoleModelling: A Theory and Paradigm for Nursing. PrenticeHall, New Jersey.

Erikson E. (1963) Childhood and Society 2nd edn. Norton, New York.

Gordon M. (1982) Nursing Diagnosis: Process and Application. McGraw-Hill, New York.

Maslow A. (1970) Motivation and Personality 2nd edn. Harper and Row, New York.

McCain R.F. (1965) Nursing by assessment-not intuition. American Journal of Nursing 65, 82-84.

Piaget J. (1973) The Psychology of Intelligence. Littlefield Adams, New Jersey.

\section{APPENDIX: Nursing assessment}

\section{Primary Source (patient)}

\section{Description of situation}

In your own words, can you tell me how you see your situation?

What do you think caused the situation to occur?

What do you think will improve the situation?

\section{Expectations}

What do you think will happen over the next few days?

What do you expect to accomplish in this hospitalization?

What is important to you at this time in your life?

Is this hospitalization affecting your long term goals?

\section{Support resources}

Who do you usually talk things over with?

Are they available to you while you are in the hospital? How often?

How is this hospitalization affecting people who are important to you?
Secondary Sources (nursing and family)

Nursing observation/analysis: Describe the patient and the situation.

Family: How does the family view the situation? Do they feel drained or have the energy to handle the situation? Family: What does the family think will improve the situation?

Nurse: What is patient's feeling state? Are there incongruences between what the patient says and non-verbal data?

Family: What do they expect to occur over the next few days? During the hospitalization?

Nurse: Does the family appear supportive? Does the patient need help interacting with health team members? Family: How is the patient's hospitalization affecting the family? 


\section{Health status}

How do you describe your general health?

Previous health problems?

Current health problems?

How do you usually handle stress?

\section{Strengths}

What do you see as the healthy or positive aspects of yourself?

Is there anything that you will need help with in caring for yourself?

Is there anything else you would like us to know about you?
Nurse: Describe patient's general appearance. Describe any pertinent alterations in physical systems.

Family: How does the family describe the patient's health?

Nurse: Additional strengths identified by the nurse.

Family: What does family see as the patient's strengths? Anything they will need help with? Anything they would like us to know?

\section{Demographical data}

Age Religion

Allergies/Sensitivities

In case of emergency contact

Patient's report of use of medications:
Name
Dose
Frequency
Last dose
Pt's reason for taking medication

Date Time Unit $\quad$ Signature


This document is a scanned copy of a printed document. No warranty is given about the accuracy of the copy. Users should refer to the original published version of the material. 